\title{
0 conceito de medicalização em Michel Foucault na década de 1970
}

Rafaela Teixeira Zorzanelli(a) Murilo Galvão Amancio $\mathrm{Cruz}^{(\mathrm{b})}$

Zorzanelli RT, Cruz MGA. The concept of medicalization in Michel Foucault in the 1970s. Interface (Botucatu). 2018; 22(66):721-31.

The aim of this paper is to describe the concept of medicalization in the work of Michel Foucault and to consider its theoretical usefulness in analyzing the phenomenon. The study is based on the hypothesis that medicalization involves two meanings according to Foucault: the first related to medicine as a social practice doled out by the State to the population; and the other related to the undefined phenomenon of medicalization, i.e., the impossibility of producing practices involving the body outside of the reach of medicine. Next, medicalization is inserted in the field of contemporary biopower, which presents a new configuration based on the emergence of the notion of risk and new biotechnologies. Last, we compare the philosopher's position with that of his contemporaries, in order to historically situate him and compare and contrast his theory with the debate about medicalization in the 1970s.

Keywords: Medicalization. Social medicine. Biopower. Biopolitics. Foucault.
Este artigo visa situar o conceito de medicalização na obra de Michel Foucault para pensar sua utilidade teórica na análise deste fenômeno. Partimos da hipótese de que a medicalização envolve dois sentidos para o autor: um relacionado à medicina como prática social que passa do Estado à população; e outro relacionado ao fenômeno da medicalização indefinida, ou seja, da impossibilidade de se produzirem práticas corporais fora do alcance da medicina. Em seguida, trataremos da medicalização inserida no campo do biopoder contemporâneo, que tem uma nova configuração a partir da emergência da noção de risco e das novas biotecnologias. Por fim, apresentaremos a posição do filósofo frente aos seus contemporâneos, a fim de situá-lo historicamente e mostrar como sua teoria se aproxima e se distancia do debate em torno da medicalização nos anos de 1970.

Palavras-chave: Medicalização. Medicina social. Biopoder. Biopolítica. Foucault.

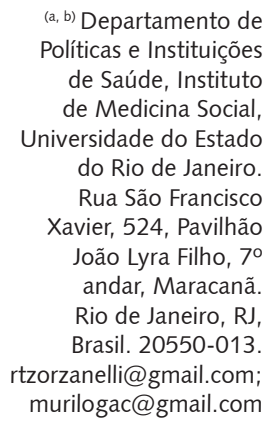

(a, b) Departamento de Políticas e Instituições de Saúde, Instituto de Medicina Social, Universidade do Estado do Rio de Janeiro. Rua São Francisco Xavier, 524, Pavilhão João Lyra Filho, $7^{\circ}$ andar, Maracanã. Rio de Janeiro, RJ Brasil. 20550-013 rtzorzanelli@gmail.com; murilogac@gmail.com 


\section{Introdução}

O tema da medicalização tem sido recorrente em diversas análises sociais sobre o campo da saúde e da doença. Todavia, o conceito de medicalização tem perdido sua especificidade teórica. Por vezes, se limita à descrição ou crítica ao poder médico. Em outras, é utilizado de maneira excessivamente abrangente, sem uma preocupação conceitual que garanta a essa ferramenta seu rigor teórico. Com efeito, esta imprecisão conceitual restringe sua utilidade e o torna um conceito monolítico e homogêneo ${ }^{1,2}$.

$\mathrm{Na}$ literatura nacional, o conceito de medicalização é amplamente abordado de maneira simplista, e, embora Foucault seja frequentemente evocado, sua teoria, bem como as nuances cronológicas que o conceito adquire em sua obra, são pouco detalhadas. Destarte, pretendemos oferecer, ao campo da Saúde Coletiva e das Ciências Humanas, uma interpretação e análise conceitual deste termo na obra do autor, durante a década de 1970, a fim de preencher esta lacuna teórica.

Tendo em vista a transitividade deste conceito ${ }^{2}$, delimitaremos, na obra do autor, suas especificidades, sobretudo, a partir de três aspectos: 1) a delimitação-conceitual, isto é, a compreensão que o autor tem sobre o fenômeno da medicalização; 2) as implicações desta teoria no dispositivo do biopoder atual; 3) o lugar histórico da teoria de Foucault frente aos seus contemporâneos.

Partimos de uma hipótese brevemente formulada em Zorzanelli et al. ${ }^{2}$ de que o termo "medicalização" apresenta dois sentidos na obra de Foucault. Um deles, compreende um fenômeno localizado entre o final do século XVII e o final do século XIX, e diz respeito ao processo de sanitarização de importantes cidades europeias que, no compasso de seu crescimento, passaram a sofrer intervenções médicas com vistas à produção da salubridade e higiene social. Este movimento foi de suma importância para o desenvolvimento das cidades e para a erradicação de algumas doenças e epidemias $^{3-5}$.

Já o segundo momento refere-se à "medicalização indefinida", que teve início ao final do século XIX e se estende até aos dias atuais. Este momento caracteriza-se por uma extrapolação da ciência médica à vida como um todo, ou seja, não haveria mais exterioridade ao saber médico nem fenômeno que não pudesse ser descrito por meio da relação do corpo com a medicina ${ }^{6-8}$.

A relação entre corpo e medicina insere o fenômeno da medicalização no campo semântico do biopoder $^{9}$. A partir desse dispositivo, pretendemos refletir sobre questões às quais os estudos mais recentes da medicalização têm se dedicado como, por exemplo, o controle de riscos e as novas biotecnologias.

Por fim, apresentaremos algumas discussões sobre o tema da medicalização contemporâneas às do filósofo, a fim de situá-lo historicamente e mostrar como sua teoria se aproxima e se distancia do debate em torno da medicalização nos anos de 1970.

\section{Formação da medicina social e sanitarização das cidades}

O tema da medicalização está ligado, no século XVIII, a três importantes passagens: 1- à biohistória, que representa o legado que a intervenção médica deixou, em um nível biológico, na história da espécie humana; 2- à medicalização propriamente dita, ou seja, ao fenômeno que integrou os diversos aspectos do ser humano em uma rede médica ampla; 3- à economia da saúde, ou seja, as consequências que as políticas tiveram na melhoria dos serviços de saúde no contexto europeu ${ }^{3}$.

Podemos entrever uma primeira definição de medicalização, que aparece em "O nascimento da medicina social": tal conceito é utilizado para descrever as intervenções médicas ao longo da história, e sob as quais a existência humana seria modificada positivamente, por meio da sanitarização das cidades, por exemplo, ou negativamente, por meio de um controle social autoritário sobre o corpo e as condutas. Para caracterizar a definição de medicalização como intervenção médica na sociedade, Foucault ${ }^{3}$ apresenta três etapas da formação da medicina social no contexto da Alemanha, França e Inglaterra que tiveram, respectivamente, como objetos da medicalização: o Estado, as cidades, e a força de trabalho. 
No contexto alemão do século XVIII, surgia a polícia médica do Estado, que tinha como finalidade controlar os fenômenos de saúde em nível estatal; normalizar a formação dos médicos, e inseri-los no grande aparelho do Estado, como funcionários administrativos. A medicina do Estado é caracterizada pela estatização e coletivização do saber médico ${ }^{3}$.

Já a França, na segunda metade do século XVIII, passava por um intenso processo de urbanização sem estrutura sanitária adequada, o que facilitava a propagação de doenças, preocupando o poder público quanto ao risco de doenças. Assim, o esquema político-médico emergente foi um aperfeiçoamento da política da quarentena, característica da Idade Média, que tinha como objetivo o isolamento e a exclusão dos doentes sob risco de contágio. Como afirma Foucault ${ }^{3}$, "Medicalizar alguém era mandá-lo para fora e, por conseguinte, purificar os outros" (p. 88). Assim, o sentido de medicalização anteriormente apresentado se complementa: não apenas como intervenção médica no nível do Estado, mas como projeto político de saneamento das cidades. O marco, portanto, da medicalização francesa foi a presença da medicina no nível administrativo das cidades, controlando os lugares possivelmente patogênicos e inaugurando uma higiene pública voltada às práticas de salubridade.

Por fim, o último objeto da medicalização na história traçada por Foucault foi a força de trabalho e a pobreza. Na Inglaterra de meados do século XIX, a população pobre deixou de ser partícipe da urbanização para ser considerada um perigo, já que fora atingida maciçamente pela epidemia de cólera em 1832. Com a lei dos pobres, se impulsiona a "organização de um serviço autoritário, não de cuidados médicos, mas de controle médico da população" ${ }^{3}$ (p. 96). Entendem-se os serviços autoritários como as práticas a partir daí impostas: obrigação de vacinação; organização do registro de epidemias; obrigação de as pessoas declararem suas doenças perigosas; localização e destruição de lugares insalubres. Este health service pretendia atingir a população em geral com medidas preventivas e higienistas. Seria "uma medicina que é essencialmente um controle da saúde e do corpo das classes mais pobres para torná-las mais aptas ao trabalho e menos perigosas às classes mais ricas"3 (p. 97).

Outro processo indispensável à higienização das cidades é a medicalização do hospital no século $X V I I I{ }^{5}$. Houve uma transformação dessa instituição, antes voltada à assistência aos pobres, para uma instituição voltada à cura. O ambiente hospitalar, que até então era um lugar para isolar a pobreza e para se morrer, torna-se uma máquina de cura, dentro da qual os procedimentos médicos se impõem ${ }^{4,5}$. Essa transformação está inserida em uma política de saúde do século XVIII, que Foucault ${ }^{4}$ denominou nosopolítica, e que se refere a uma política social que tem a saúde como um ideal e uma responsabilidade de todos.

A medicalização da família, e a infância como período privilegiado de intervenção médica, são características dessa nosopolítica, que transforma a família no "agente mais constante da medicalização" 4 (p. 199), assumindo seu objetivo central, que é o dever de cada indivíduo com a sua saúde e, ao mesmo tempo, com a saúde geral da população. Não é sem motivo que as quatro estratégias do dispositivo da sexualidade giram em torno da família: a histericização dos corpos femininos; a pedagogização do sexo das crianças; a psiquiatrização do prazer perverso/adulto; e a socialização das condutas de procriação ${ }^{8}$.

Nesse contexto, a higiene e o funcionamento da medicina são, ao mesmo tempo, instâncias de controle social e moral. O objetivo da higiene pública, relacionado à eliminação das doenças epidêmicas, gerou, como subproduto, a classificação daqueles que nessas práticas se enquadravam e os que não.

A medicina como técnica geral de saúde [...] assume um lugar cada vez mais importante nas estruturas administrativas e nesta maquinaria de poder que, durante o século XVIII, não cessa de se estender e de se afirmar. O médico penetra em diferentes instâncias de poder. [...]. E constitui-se, igualmente, uma ascendência político-médica sobre uma população que se enquadra com uma série de prescrições que dizem respeito não só à doença mas às formas gerais da existência e do comportamento ${ }^{4}$. (p. 202) 


\section{A medicalização indefinida}

O que Foucault ${ }^{3}$ apresenta ao traçar a história da medicina social no contexto europeu dos séculos XVIII e XIX é, entre outros pontos, o caminho de ampliação dos objetos da medicina, ou seja, o processo pelo qual a intervenção médica passa a incluir, no âmbito de sua ação, objetos e alvos que a priori não faziam parte dele. O estado, a cidade e a pobreza tornaram-se objetos de interesse e intervenção médica no decorrer dos três séculos que precederam a explosão do fenômeno da medicalização, no início do século XX. De certa forma, quando a medicina adentrou esse espaço social, ela preparou o terreno para que o exercício biopolítico da medicalização sem fronteiras fosse possível e efetivo no século XX e perdurasse até o século XXI.

Este outro sentido, mais contemporâneo, não exclui o anterior. De fato, o processo de medicalização continua se referindo a uma intervenção médica, muitas vezes, autoritária. Entretanto, não mais relacionada apenas ao nível da política, mas a todo e qualquer aspecto da vida humana. Não se restringe, portanto, a aspectos autoritários, mas engloba modulações específicas, ainda não previstas no saber médico do século XVIII e XIX. Os dois sentidos são complementares, embora distintos na cronologia histórica.

Os modelos de medicina social desenvolvidos a partir do século XVIII marcaram o processo de ascensão sanitária do velho mundo e foram acompanhados por um desbloqueio técnico e epistemológico importante ${ }^{3,6}$. Para Foucault ${ }^{6}$, é essa ascensão que conduziu a medicina pós-1950 a uma crise baseada, paradoxalmente, no potencial do que o saber médico pode realizar - e não em suas lacunas e insuficiências ${ }^{(c)}$. Seria a amplitude do que o saber médico abrange, os instrumentos de que dispõe, a eficácia de seus procedimentos e os efeitos que alcança o que torna o saber médico mais nocivo, fazendo os indivíduos adentrarem em um campo de probabilidades e riscos que pouco se pode controlar'.

Esta crise da ciência médica, no século $X X$, teria como ponto crucial o final da Segunda Guerra Mundial e o plano Beveridge ${ }^{(d)}$ de seguridade social. Como consequência, emergiria a "medicalização indefinida". Se, no século XVIII, a medicalização das cidades foi de suma importância para o desenvolvimento social, o segundo episódio da medicalização, mais contemporâneo, é maior alvo de interesse na atualidade, por sua capacidade de ampliação do campo de intervenção médica. É que, no século $X X$, a medicina perdeu, efetivamente, suas fronteiras e passou a ocupar todo o campo social fora da demanda do sujeito. A medicina passou, então, a fazer parte do cotidiano de todos, como uma intervenção sem demanda, incorporada à sexualidade, às escolas, às famílias e aos tribunais. Exemplificando, Foucault ${ }^{6}$ afirma: "A intervenção sistemática de um terapeuta médico junto a homossexuais dos países da Europa Oriental é característica da medicalização de um objeto que nem para o sujeito, nem para o médico constitui uma doença" (p. 384).

Já não se fala somente da obrigação da limpeza e da higiene para gozar de boa saúde, mas de fenômenos da vida cotidiana que entram no campo de ação do saber médico. As práticas médicas estão em todos os lugares, à medida que a saúde se torna um objeto de desejo e de lucro. Modificou-se a atenção da medicina novecentista com agentes patogênicos dos corpos segregados e confinados para o cultivo individual do corpo saudável, exaltado como um ideal. Houve um deslocamento do sonho higienista de isolar e erradicar a doença para um modelo de responsabilidade individual pela saúde. Esse deslocamento é exatamente do que trata o conceito de medicalização hoje. (c) Vale dizer que o debate que Foucault traça em torno desta noção de crise da medicina ou da antimedicina está em franco diálogo com a obra de Illich ${ }^{10}$, que apresentaremos adiante.

(d) O plano ou relatório Beveridge foi uma forma de seguridade social cujo objetivo era reparar os danos causados pela guerra a partir de propostas de reformas sociais abrangentes. Segundo Foucault ${ }^{6}$, este plano é o responsável por dar, ao Estado, a responsabilidade pela saúde de seus povos. 
A medicina posterior à segunda metade do século $X X$, indefinida e sem limites, foi muito além da busca pela salubridade. Esse movimento em direção à medicalização está relacionado a, pelo menos, quatro processos técnico-administrativos que caracterizam a medicina moderna que se iniciou no final do século XVII: a) autoridade médica; b) ampliação do seu campo de intervenção; c) hospital como aparelho de medicalização coletiva; d) introdução de mecanismos de administração médica, como registros e estatísticas. Assim, com o avanço da medicina para além de suas fronteiras, não há mais "domínio que lhe seja exterior"6 (p. 386).

Como vimos, os episódios que marcaram os séculos XVIII e XIX em relação à saúde da população são cruciais para o entendimento do processo de medicalização no século XX, que avança em direção ao presente. Importantes transformações ocorreram tanto no campo do saber-poder quanto no lugar que o corpo e o sujeito passaram a ocupar na sociedade. Pretendemos, adiante, passar a uma análise biopolítica do processo de medicalização a fim de compreender certa transformação do corpo para uma sociedade em que a medicalização se realiza como fenômeno histórico.

\section{A medicalização inserida no dispositivo do biopoder contemporâneo}

Em 1976, Foucault inicia uma de suas aulas descrevendo um dos fenômenos fundamentais do século XIX, a saber: "a assunção da vida pelo poder [...] [ou seja], uma tomada de poder sobre o homem enquanto ser vivo, uma espécie de estatização do biológico" (p. 286).

De fato, é o momento no qual as características biológicas entrarão numa estratégia de poder e

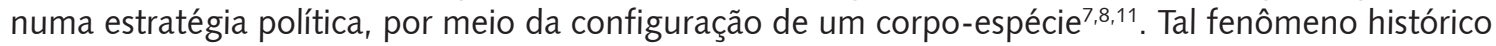
que coloca a vida no campo político do saber e poder está diretamente relacionado aos sentidos que o conceito de medicalização adquire na obra do filósofo.

Afinal, esse momento coincide com uma inversão política: se antes o poder do soberano era exercido a partir do direito de fazer morrer, agora o que se instalava era o direito de fazer viver ${ }^{7,8}$. O direito soberano sobre a morte se transfere para a vida, a fim de geri-la. A vida será empreendida por um poder que se preocupa em administrá-la em todas suas instâncias, desde a reprodução até a regulação e controle contínuos.

Segundo Esposito ${ }^{12}$, o conceito de biopolítica é marcado por uma incerteza que impede sua definição estável. Afinal, a dialética entre vida e política seria irredutível a qualquer síntese de causa única. Nesse sentido, apresentamos, a seguir, uma breve distinção conceitual, que auxilia no entendimento do fenômeno da medicalização, e diz respeito à extrapolação dos limites da coerção disciplinar pela biopolítica, dado que, embora haja uma relação desta com as disciplinas, não há uma coincidência exata da biopolítica com o poder coercitivo da soberania. Pelo contrário, a biopolítica implicaria uma expansão das forças vitais, que pode, por conseguinte, ser também capturada ${ }^{12}$.

Todavia, há um poder que se apropria das peculiaridades desta relação dos corpos dos indivíduos com os seus processos vitais. Este se denomina "biopoder" e desenvolveu-se a partir do século XVII em duas formas principais que não são excludentes, mas complementares ${ }^{9,13}$. A primeira, a partir do século XVII, sob a forma da anatomopolítica do corpo e dos procedimentos disciplinares. Tais procedimentos tinham como função extrair do corpo sua força útil, a partir de uma tecnologia de poder centrada no corpo enquanto máquina, isto é, um corpo passível de ser adestrado e ampliado para gerar força de trabalho ao sistema econômico. É a produção de um corpo dócil voltado à produção. Este poder sobre o corpo-individual é o que caracteriza o poder disciplinar,8,13.

A segunda vicissitude surgiu pouco mais tarde, por volta da metade do século XVIII, e retirou do corpo individual a vida da espécie. Agora o que interessava a esse poder era a vida do ser vivo em seus processos biológicos, isto é, em sua capacidade de reprodução, suas taxas de natalidade/mortalidade, longevidade, entre outros fenômenos próprios à vida que passam a ser objetos de intervenção política. Este poder sobre o corpo-espécie é a característica da biopolítica, $, 9,13$.

A associação entre o poder sobre o corpo-individual e o poder sobre o corpo-espécie, que ocorreu a partir do século XIX, caracteriza o "biopoder"8,13. Um poder cuja tecnologia une dois elementos indispensáveis para o controle da vida: os desempenhos do corpo e os processos vitais. As instituições disciplinares e a biopolítica formam uma aliança útil no exercício da gestão da vida, que encontra, 
no fenômeno da medicalização, um lugar de ação, visto que a medicalização se caracteriza pela intervenção médica sobre o plano da vida dos sujeitos, exercendo um controle sobre a população e o indivíduo.

Rabinow \& Rose $^{9}$, ao tratarem do conceito de biopoder na atualidade, em que se evidencia uma expansão da tecnologia médica, destacam três características essenciais do fenômeno, que seriam: 1) a apresentação de um discurso de verdade sobre os sujeitos por uma autoridade considerada apropriada para tal; 2) a intervenção sobre a realidade coletiva, em nome da vida; 3) a produção de sujeitos alicerçados aos discursos de verdade, sobretudo, relacionados à saúde e doença. Com efeito, o elo medicalização e biopoder se estabelece.

A medicalização inserida no dispositivo do biopoder centra-se nessas características. Afinal, ela se exerce em nome de um discurso científico que produz intervenção sobre a sociedade e, consequentemente, processos de subjetivação. Segundo Dreyfus \& Rabinow ${ }^{13}$, a intensificação das intervenções no nível da vida da população resultou em uma animalização do homem que, por meio de técnicas biopolíticas, foi submetido a processos de modulação contínuos. A valer, efetivouse o controle sobre a vida, o que gerou repercussões de múltiplas qualidades: desde o controle de epidemias até a medicalização dos comportamentos e dos desvios.

\section{Controle de riscos e novas biotecnologias}

O que está em pauta com o conceito de biopolítica é uma modalidade de controle e de regulação social dos corpos pela normalização das individualidades, cujo registro está diretamente relacionado à produção de riqueza. Agamben ${ }^{14}$ sugere estar na politização da vida o evento marcante da modernidade, aquilo que uniu a vida nua (zoé, isto é, a vida comum ao vivente) à existência política (biós, ou seja, o modo de viver a própria vida), numa relação de exclusão inclusiva. Com efeito, a vida nua é excluída no processo de expropriação da potência humana pelo poder que modula essa mesma vida a partir de uma biopolítica. Entretanto, é nesse jogo de exclusão da vida nua que esta passa a fazer parte do espaço político, ou seja, que ela é incluída. Afinal, segundo Agamben ${ }^{14}$, a vida nua é uma produção do poder que tem como consequência uma indistinção entre zoé e biós, ou seja, uma indistinção entre a vida orgânica e a vida politizada.

A biologia é o instrumento por excelência da biopolítica, em suas diferentes derivações, e a medicina é o espaço por excelência de sua operacionalização, disseminação e catalisação no espaço social. Nesse sentido, propaga-se, por meio desses mecanismos de controle, um ideal de corporeidade em que a saúde é um valor supremo, a ser buscado tanto individualmente quanto pela população. Surge uma noção de perigo eminente de doença, e os riscos de adoecer tornam-se elementos fundamentais para a regulamentação da vida, que tem a medicina como elemento fundamental na consolidação de uma união entre o poder disciplinar e o poder de regulamentação, que agem por meio da norma:

o elemento que vai circular entre o disciplinar e o regulamentador, que vai se aplicar, da mesma forma, ao corpo e à população, que permite a um só tempo controlar a ordem disciplinar do corpo e os acontecimentos aleatórios de uma multiplicidade biológica, esse elemento que circula entre um e outro é a "norma"7. (p. 302)

É dentro desse contexto que se deve compreender a importância estratégica assumida pela medicalização da vida na constituição e no desenvolvimento da biopolítica, sobretudo no que diz respeito à relação entre a saúde e a produção de si mesmo. O campo biomédico foi importante, não somente no processo de tornar o ser humano um objeto em torno do qual se produziu um saber dito científico, como Foucault ${ }^{15}$ destacou desde "O nascimento da clínica", mas por orientar formas de governar as pessoas, individual e coletivamente. Nesse governo da vida, os especialistas médicos, em aliança com as autoridades políticas, manejaram meios de viver para minimizar doenças e promover a saúde da população $0^{3,4}$. Desde então, podemos pressupor uma evidente associação entre a construção de formas de subjetivar-se e as noções de saúde, doença e tratamento9,16. 
A esse respeito, Clarke et al. ${ }^{16}$ apontam que, desde 1985, novas tecnologias emergem e direcionam os estudos acerca do normal e do patológico na era da biomedicina. Elas realizam uma transformação não apenas no nível técnico da ciência, mas ideológico, que diz respeito à forma como cada sujeito vivenciará os estados de saúde e doença. As biotecnologias recentes se colocaram em favor do biopoder, nessa dupla atuação sobre o corpo e sobre a espécie, a partir da noção de uma medicina sem demanda: técnicas de screening e rastreamento de doenças na população, que não respondem à solicitação do doente, constituem-se como práticas esperadas de responsabilidade individual. Clarke et al. ${ }^{16}$ denominaram esta transformação, no campo das ciências biomédicas, de "biomedicalização".

A questão é que a biomedicalização impõe novas vertentes sobre a antiga medicalização. Se, antes, o comportamento desviante, por exemplo, fora considerado um estado patológico contra o qual se devia lutar por meio de tratamento médico, esta transformação discursiva tem sido modificada. A experiência de estar em risco de adoecer se converteu em doença ela mesma ${ }^{17-19}$. Noções como a de pré-doença ganham as mais diferentes áreas da medicina e encantam os pacientes, que recebem tratamento cada vez mais precocemente e frequentemente idêntico ao quadro clínico manifesto (hipercolesterolemia, pré-diabetes ou estados mentais de risco ${ }^{17,19}$ ). Isso traz desdobramentos nas decisões médicas, cuja consequência é, sobretudo, um "novo jeito de vivenciar doença e saúde muito marcado pelo risco"18 (p. 418). Observa-se um aumento do espectro de pessoas incluídas no risco para diferentes doenças, atrelado: à expansão do mercado de intervenções; às mudanças na percepção da severidade das doenças; e ao maior recrutamento de populações por meio de tecnologias de rastreio e diagnóstico ${ }^{18}$.

Nesse contexto, Gaudenzi ${ }^{20}$ denominou mutações biopolíticas as transformações contemporâneas a que estamos submetidos. Os novos modos de subjetivação não estão mais atrelados aos cálculos da vida e da morte, característica da biopolítica do século XX, mas relacionados à nova era da biomedicina do século XXI. A autora aponta que, desde o início deste século, a subjetividade passou a ser definida em termos de identidades corporais e intervenções biotecnológicas ${ }^{20}$. Três consequências são resultados deste processo: a gestão do risco por meio das tecnologias de screening, o desejo pelo aprimoramento das capacidades humanas (enhancement), e uma exacerbação do cuidado de si, ou seja, uma busca pelo corpo e pela saúde ideal.

Nesse sentido, a medicina de intervenção autoritária - na qual Foucault ${ }^{3}$ se detém ao falar da formação das práticas higienistas na Europa - está em um campo cada vez mais amplo da existência individual e coletiva, e acirrou-se no decorrer do século XX e XXI, sob outros modos. Hoje, a medicina está dotada de um poder autoritário com funções normalizadoras que extrapolam a existência das doenças e das demandas do doente. O século XX inventou, no campo médico, uma sociedade regida pela norma, na qual o que importa não são somente códigos e leis a cumprir, mas o manejo da distinção tênue entre normal e anormal, afinal, a "medicina é um saber-poder que incide ao mesmo tempo sobre o corpo e sobre a população, sobre o organismo e sobre os processos biológicos e que vai, portanto, ter efeitos disciplinares e efeitos regulamentadores"7 (p. 302).

No entanto, se a sexualidade era um foco de incidência articulador do corpo próprio à vida da espécie, como enfatizou Foucault7,8, nessas obras do final de 1970, encontramos, no cenário do século $X X I$, uma série de outros valores sobre os quais se pode agir para promover uma capitalização da vida: DNA, os órgãos e tecidos humanos, as células-tronco, oócitos. Um repertório de procedimentos biotecnológicos pode ser desenvolvido para induzir um fragmento molecular a se expandir, acelerar seus processos intrínsecos, a se recombinar, a desenvolver capacidades inéditas, otimizando processos vitais. O que se pode testemunhar é o aumento de vitalidade produzida pela reformulação biológica em nível molecular, que abre um novo campo biopolítico ${ }^{21}$.

Estamos frente a um fenômeno ideológico que coloca a saúde como um ideal de prosperidade na sociedade contemporânea, em que os mínimos riscos de adoecer devem ser eliminados em nome do bem-estar e, portanto, a saúde deve ser uma busca constante ainda que não se tenha adoecido. Estamos diante do acirramento de novas modulações da saúde perfeita, que inclui o healthism, tal como o definiu Crawford ${ }^{22}$, que é um modo particular de compreender a saúde como bem maior a ser conquistado. O estilo de vida saudável passa a ser um way of being, que busca uma "super saúde". No atual panorama biopolítico que descrevemos, o healthism está diretamente relacionado à gestão 
dos riscos, uma vez que ao colocar o nível da saúde como ideal a se perseguir, são forjados estilos de vida que se baseiam essencialmente na prevenção de condutas e comportamentos de risco ${ }^{23}$.

\section{Foucault e seus contemporâneos}

A produção de Foucault acerca da medicalização está inserida no contexto de produção mais amplo da década de 1970; é nela que o tema da medicalização ganha grande repercussão, com algumas publicações de destaque: Zola ${ }^{24}$, Szasz $^{25}$, Illich ${ }^{10}$, Conrad ${ }^{26}$. Todavia, embora contemporâneos, os processos aos quais Foucault se dedica dizem respeito a sentidos diferentes do que aqueles tratados pelos autores supracitados. Em Foucault, como fizemos ver, os sentidos estão ligados a: 1) processo de sanitarização, urbanização e, consequente, desenvolvimento da higiene pública sanitária; e 2) processo de apagamento das fronteiras entre a medicina e a vida como um todo, ou seja, o processo de medicalização indefinida.

Em contrapartida, nos escritos de Zola ${ }^{24}$ e Illich ${ }^{10}$, o processo de medicalização é, "grosso modo", um efeito do imperialismo da profissão médica sobre os indivíduos, como uma forma de regulação social e perda de suas autonomias. Já em Szasz ${ }^{25}$, o que está em questão são os transtornos psiquiátricos que se expandem e passam a abarcar os problemas cotidianos do comportamento humano a partir da expertise psiquiátrica. Em Conrad ${ }^{26}$, por sua vez, o processo de medicalização está relacionado à "definição de um comportamento como um problema médico e licenciar à profissão a oferta de algum tipo de tratamento" (p. 12), perspectiva adotada desde o seu primeiro estudo de caso, que é a hipercinese. Sua definição, desde as obras iniciais até suas obras mais recentes, não mudou significativamente, e enfatizam o papel da medicina na tomada de posição em definir e tratar um determinado tipo de conduta.

De modo geral, podemos apontar um primeiro e importante ponto destoante: é que os fenômenos de que trata Foucault e seus contemporâneos não estão situados no mesmo contexto histórico. Enquanto Foucault, ao menos no primeiro sentido do termo, ao tratar de medicalização, se refere a um processo advindo, sobretudo, do século XVIII, na constituição das nações europeias, seus contemporâneos tratam de um processo típico do século XX. Esse é um importante ponto de confusão gerado pelos leitores apressados dos autores citados. Entretanto, uma importante semelhança entre eles é a crítica contundente ao saber e às instituições médicas que se impõem de modo autoritário aos indivíduos como forma de controle social.

Lupton ${ }^{27}$ realiza uma separação entre o que ela chama de perspectiva foucaultiana sobre a medicalização e uma perspectiva de crítica ortodoxa à medicalização. Para a autora, Foucault, ao longo de sua obra, elabora uma compreensão complexa sobre como a vida é experimentada e compreendida por meio dos discursos e práticas do saber médico. Entretanto, para os ortodoxos da tese da medicalização, a situação parece ser reduzida ao poder médico do Estado capitalista. É como se a medicalização infligisse apenas perda da autonomia, regulação da vida e controle social, tendo um viés sempre pejorativo, ou seja, um estado contra o qual devemos resistir. Na visão da autora, os ortodoxos colocam, na figura do médico, um poder autônomo, e, nos pacientes, uma passividade extrema, ignorando o lugar de sujeito dos pacientes, que também são agentes do processo de medicalização, por exemplo, quando invocam o saber médico em prol da luta por acesso aos direitos de determinados grupos. Além disso, ignora-se a contribuição do saber médico para saúde e alívio da dor ${ }^{27}$.

Tratar minuciosamente de cada diferença e semelhança entre Foucault e seus contemporâneos não é nosso objetivo. No entanto, faz-se importante ressaltar que a tese do imperialismo médico, sobre a qual autores como Szasz ${ }^{25}$ e Zola ${ }^{24}$ sustentam seus trabalhos, é incompatível com a visão foucaultiana de uma medicina "sem fora", isto é, em que não haveria indivíduos ou qualquer espaço político em sociedades ocidentais liberais urbanas que fossem isentos de alguma forma de presença de saber médico (diagnóstico, procedimentos, prioridade à ciência, dentre outros). Além disso, é difícil pensar no conceito de imperialismo médico, tamanha é a mistura do saber médico com outras formas de saber e também com outras formas de controle social. Ademais, a "medicina" como entidade abstrata faz pouco ou nenhum sentido para ser descrita sem especificidade e, portanto, não pode imperializar nada, porque não está sobre nenhuma esfera, nem acima, nem dentro. É como se a política, a 
sociedade, e outras engrenagens fossem todas articuladas no e pelo saber médico.

Assim, a medicina em suas especificidades ocuparia, tal como Foucault nos aponta ${ }^{6}$, todos os lugares sociais na contemporaneidade, não se concentrando, portanto, em nenhuma conjuntura da instituição médica socialmente circunscrita, como se fosse dotada de um poder vertical sobre as redes de indivíduos. Vale mencionar que Conrad ${ }^{26}$ se aproxima desta ideia de Foucault por outros meios, ao descentrar a ideia do médico como protagonista do processo de medicalização, demonstrando que atores diversos podem desempenhar papéis cruciais em processos de medicalização, tais como movimentos sociais, coletivos e grupos organizados.

\section{Considerações finais}

O processo de medicalização da sociedade é comumente caracterizado por uma transformação de objeto do saber médico, isto é, uma reinvenção sobre quais seriam os objetos da ciência médica e que, portanto, seriam passíveis de sua intervenção. A partir disso, a ciência médica passou a abarcar questões que, a priori, não pertenciam ao domínio médico, mas aos campos político, social e econômico ${ }^{28}$. Decerto, esta é uma descrição genérica do termo, que suprime especificidades. Nosso objetivo foi, portanto, expor a compreensão foucaultiana acerca do tema que não necessariamente exclui outras perspectivas, mas que guarda especificidades históricas e conceituais em relação a outros autores.

Procuramos demonstrar, a partir dos textos de Foucault sobre o tema, como, a partir do século XVII, a emergência de uma medicina social, que atinge o Estado, as cidades e a força de trabalho, culminou em uma medicalização da sociedade, caracterizada pela sanitarização pública, tendo sido esse o primeiro momento descrito por Foucault ${ }^{3,4}$ em que a medicina se apropriou de diferentes aspectos da vida humana. No entanto, dado o caráter expansivo da ciência médica e a consolidação de um biopoder, encontramos, no início do século XX até os dias de hoje, outra característica da medicalização. Não mais aquela ligada à higiene pública, mas à ampliação de seu espectro, em que não existiria um "fora" da medicina. Pelo contrário, o saber médico - seu vocabulário, as injunções a que ele dá lugar, seus objetos de interesse - atingiria a vida social como um todo ${ }^{6-8}$. Nesse sentido, a medicalização de que trata o autor é um dispositivo central do exercício do que se chamaria de nascimento do biopoder ${ }^{7,8,13}$. A flutuação e a incerteza acerca dos limites da medicalização provêm do caráter múltiplo e complexo dos elementos aqui descritos.

É interessante notar que, para o autor, o século XIX ainda continha domínios que permaneciam "não médicos" e que pareciam não "medicalizáveis" 3 . Era possível conceber uma dimensão exterior à medicina, em que práticas corporais, de higiene, e uma moral da sexualidade ainda não eram por ela controladas nem codificadas. Na situação atual, quando se quer recorrer a esse domínio exterior, descobre-se que ele já foi medicalizado. E quando se quer objetar à medicina suas deficiências, seus inconvenientes e seus efeitos nocivos, isso é feito em nome de um saber médico mais completo, mais refinado e difuso. É nesse sentido que Foucault ${ }^{6}$ vai advogar que vivemos um estado em que não há mais fora da medicina.

O processo de medicalização que se intensificou e passou a agrupar o fenômeno do risco de adoecer está intrinsecamente ligado ao fenômeno do biopoder característico do século XVIII e XIX. De fato, a medicina é o elo que articula a biopolítica com a disciplina, isto é, o elo do biopoder no controle da vida, que atua por meio da noção de norma. É o que assistimos nas mudanças que as formas de vigilância sobre o corpo, sobre a doença e sobre a saúde atuam, por meio da noção de risco e das novas biotecnologias, possibilitando autores contemporâneos repensarem os próprios sentidos de medicalização hoje.

Em meio a inúmeras teses e hipóteses acerca da medicalização, encontramos em Foucault uma compreensão eminentemente histórica, em que tal fenômeno se articula com os processos de subjetivação, desenvolvimento social e produção de saber e poder. De fato, o marcante na obra de Foucault é seu caráter transitório, que não se limita a uma análise negativa ou positiva sobre a incidência do poder sobre a vida - pelo qual o fenômeno da medicalização se apresenta -, mas evidencia um processo complexo do qual múltiplos atores fazem parte. 


\section{Colaboradores}

Os autores participaram igualmente da elaboração do texto. A hipótese principal foi formulada por Rafaela Teixeira Zorzanelli, mas, em seguida, discutida e ampliada em parceria com Murilo Galvão Amancio Cruz. Ao final, ambos os autores participaram ativamente da discussão teórica, revisando e aprovando a versão final do artigo.

\section{Referências}

1. Rose N. Beyond medicalisation. Lancet. 2007; 369(9562):700-2.

2. Zorzanelli RT, Ortega F, Bezerra Junior B. Um panorama sobre as variações em torno do conceito de medicalização entre 1950-2010. Cienc Saude Colet. 2014; 19(6):1859-68.

3. Foucault M. O nascimento da medicina social. In: Machado R, organizador. Microfísica do poder. São Paulo: Graal; 1984. p. 79-98.

4. Foucault M. A política da saúde no século XVIII. In: Machado R, organizador. Microfísica do poder. São Paulo: Graal; 1984. p. 193-208.

5. Foucault M. O nascimento do hospital. In: Machado R, organizador. Microfísica do poder. São Paulo: Graal; 1984. p. 99-111.

6. Foucault M. Crise da medicina ou crise da antimedicina? In: Motta MB, organizador. Arte, epistemologia, filosofia e história da medicina. Rio de Janeiro: Forense-Universitária; 2011. p. 374-393. (Coleção Ditos e Escritos VII).

7. Foucault M. Aula de 17 de março de 1976. Em defesa da sociedade: curso no Collège de France. São Paulo: Martins Fontes; 1999. p. 285-315.

8. Foucault M. História da sexualidade I: a vontade de saber. Rio de Janeiro: Graal; 1988.

9. Rabinow P, Rose N. O conceito de biopoder hoje. Polit Trab Rev Cienc Soc. 2006; 24:27-57.

10. Illich I. Medical nemesis: the expropriation of health. London: Marion Boyars; 1976.

11. Foucault M. Aula de 11 de janeiro de 1978. Segurança, território, população: curso no Collège de France. São Paulo: Martins Fontes; 2008. p. 3-38.

12. Esposito R. Bios: biopolitics and philosophy. Minneapolis: University of Minnesota Press; 2008.

13. Dreyfus $H$, Rabinow P. Michel Foucault uma trajetória filosófica: para além do estruturalismo e da hermenêutica. Rio de Janeiro: Forense-Universitária; 1995.

14. Agamben G. Homo Sacer: o poder soberano e a vida nua I. Belo Horizonte: Editora UFMG; 2002.

15. Foucault M. O nascimento da clínica. Rio de Janeiro: Forense-Universitária; 1998.

16. Clarke AE, Shim JK, Mamo L, Fosket JR, Fishman JR. Biomedicalization: technoscientific transformations of health, illness, and U.S. biomedicine. Am Sociol Rev. 2003; 68(2):161-94.

17. Greene JA. Prescribing by numbers: drugs and the definition of disease. Baltimore: Johns Hopkins University Press; 2007.

18. Aronowitz RA. The converged experience of risk and disease. Milbank Q. 2009; $87(2): 417-442$.

19. Dumit J. Drugs for life: how pharmaceutical companies define our health. Durham: Duke University Press; 2012.

20. Gaudenzi P. Mutações biopolíticas e discursos sobre o normal: atualizações 
foucaultianas na era biotecnológica. Interface (Botucatu). 2017; 21(60):99-110.

21. Rose N. A política da própria vida: biomedicina, poder e subjetividade no século XXI. São Paulo: Paulus; 2013.

22. Crawford R. Healthism and the medicalization of everyday life. Int J Health Serv. 1980; 10(3):365-88.

23. Castiel LD, Guilam MCR, Ferreira MS. Correndo o risco: uma introdução aos riscos em saúde. Rio de Janeiro: Fiocruz; 2010.

24. Zola I. Medicine as an Institution of social control. Sociol Rev. 1972; 20(4):487-504.

25. Szasz T. The myth of mental illness: foundations of a theory of personal conduct. New York: Harper Row; 1974.

26. Conrad P. The discovery of hyperkinesis: notes on the medicalization of deviant behavior. Soc Probl. 1975; 23(1):12-21.

27. Lupton D. Foucault and the medicalisation critique. In: Petersen A, Bunton R, organizadores. Foucault, health and medicine. London: Routledge; 1997. p. 94-110.

28. Conrad P. The medicalization of society: on the transformation of human conditions into treatable disorders. Baltimore: Johns Hopkins University Press; 2007.

Zorzanelli RT, Cruz MGA. El concepto de medicalización en Michel Foucault en la década de 1970. Interface (Botucatu). 2018; 22(66):721-31.

El objetivo de este artículo es situar el concepto de medicalización en la obra de Michel Foucault para pensar su utilidad teórica en el análisis de este fenómeno. Partimos de la hipótesis de que la medicalización envuelve dos sentidos para el autor: uno relacionado con la medicina como práctica social que pasa del Estado a la población y otro relacionado con el fenómeno de la medicalización indefinida, es decir, de la imposibilidad de que se produzcan prácticas corporales fuera del alcance de la medicina. A continuación, trataremos de la medicalización inserida en el campo del biopoder contemporáneo, que tiene una nueva configuración a partir de la emergencia de la noción de riesgo y de las nuevas biotecnologías. Finalmente, presentaremos la posición del filósofo ante sus contemporáneos con la finalidad de situarlo históricamente y mostrar como su teoría se aproxima y se distancia del debate alrededor de la medicalización en la década de 1970.

Palabras clave: Medicalización. Medicina social. Biopoder. Biopolítica. Foucault. 
